\title{
ARTICLE
}

\section{Phenotype-genotype correlation in familial Mediterranean fever: evidence for an association between Met694Val and amyloidosis}

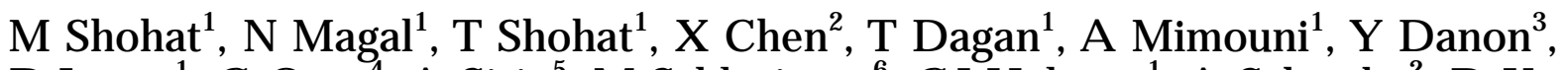

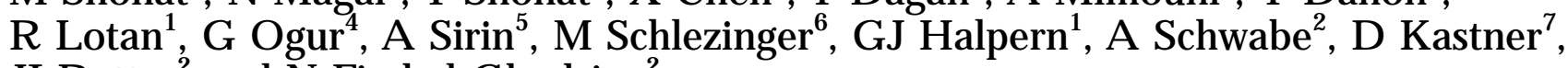 \\ JI R otter ${ }^{2}$ and N Fischel-G hodsian ${ }^{2}$ \\ ${ }^{1}$ D epartment of M edical G enetics, FM RC and B eilinson Campus, Rabin M edical Center and Sackler School of \\ $M$ edicine, Tel A viv U niversity, I srael \\ ${ }^{2}$ M edical G enetics B irth D efects Center, Cedars-Sinai M edical Center and UCL A, L os A ngeles, CA, USA \\ ${ }^{3} \mathrm{D}$ epartment of Immunology, FM RC and B eilinson Campus, Rabin M edical Center and Sackler School of M edicine, \\ Tel A viv U niversity, I srael \\ ${ }^{4} \mathrm{M}$ edical $\mathrm{G}$ enetics, $\mathrm{G}$ ata M edical Center and I mmunology D epartment, A nkara U niversity M edical Faculty, A nkara \\ ${ }^{5}$ Pediatric N ephrology, I stanbul M edical Faculty, U niversity of I stanbul, Turkey \\ ${ }^{6}$ I mmunology U nit, B arzilai M edical Center, A shkelon, I srael \\ ${ }^{7} \mathrm{~A}$ rthritis and R heumatism B ranch, $\mathrm{N}$ ational Institute of A rthritis and M usculoskeletal and Skin Diseases, Bethesda, \\ M aryland, USA
}

\begin{abstract}
Familial Mediterranean fever (FMF) is an autosomal recessive disease characterised by recurrent attacks of inflammation of serosal membranes. A myloidosis is the most severe complication of the disease. The aim of this study was to investigate the genotype-phenotype correlation and specifically the association between amyloidosis and the four common mutations in exon 10 of the gene causing FMF (MEFV) in a total of 83FMF families from three ethnic groups: N orth A frican Jews, A rmenians and Turks. A significant association was found between amyloidosis and the specific mutation at the MEFV gene: Met694Val $(R R=1.41, P=0.02)$. A myloidosis was present in 18 out of 87 homozygous FMF patients $(20.7 \%)$ and in only two out of the 41 compound heterozygous FM F patients $(4.9 \%)$. No patients carrying other mutations had amyloidosis. There was no significant association between the various mutations and the type or severity of the FMF symptoms. This finding underscores the importance of performing molecular studies on all suspect FM F patients. In addition to providing accurate diagnosis, these tests allow identification of presymptomatic genetically affected individuals, detection of carriers and assessment of the risk for amyloidosis in later life.
\end{abstract}

Correspondence: Mordechai Shohat MD, Director, Department of M edical Genetics, R abin Medical Center, B eilinson Campus, Petah Tikva, 49100, I srael. Tel: + 9723937 7658/9; Fax: +9723937 7660; E-mail: mshohat@ccsg.tau.ac.il

R eceived 20 A ugust 1998; revised 280 ctober 1998; accepted 11 N ovember 1998 


\section{Keywords: phenotype-genotype correlation; amyloidosis; specific mutation}

\section{Introduction}

Familial Mediterranean fever (FMF) is an autosomal recessive disease affecting mainly non-A shkenazi Jews (NA J), A rmenians, Turks and A rabs. ${ }^{1}$ The carrier rate in these populations is very high, with estimates based on family studies as high as 1:5-1:7 among some nonA shkenazi J ewish populations, ${ }^{2}$ and 1:7 among A rmenians in California. ${ }^{3}$ The disease is characterised by recurrent short episodes of inflammation and serositis including fever, peritonitis, pleuritis, synovitis ${ }^{1,3,4}$ and rarely pericarditis. ${ }^{5}$

A myloidosis, similar to that seen in other chronic inflammatory diseases such as rheumatoid arthritis, is the most severe complication of $\mathrm{FM} \mathrm{F}$ and leads to renal failure. In untreated J ewish patients of North A frican origin the frequency of amyloidosis increases progressively with age, occurring in up to $75 \%$ of those over 43 years. ${ }^{6}$ There is ethnic variability in the prevalence of amyloidosis, which occurs in $60 \%$ of the Turks, in $27 \%$ of the non-A shkenazi Jews, and in $1-2 \%$ of the A rmenians in the U nited States. ${ }^{7}$ Colchicine has been shown to be effective in preventing the attacks of $F M F$ as well as the development of amyloidosis. ${ }^{8-10}$ Some individuals develop amyloidosis without having recurrent inflammatory episodes (FM F type 2). ${ }^{11}$ Therefore, identification of an amyloidosis-associated mutation will allow for directing prophylactic colchicine therapy to presymptomatic individuals who can greatly benefit from it.

Linkage between the gene responsible for $\mathrm{FMF}$ (MEFV) and the short arm of chromosome 16 was first shown in $1992 .{ }^{12}$ L ocus homogeneity was demonstrated for all ethnic groups studied. ${ }^{13}$ Recently, the gene causing FM F has been cloned, ${ }^{14,15}$ and four common missense mutations identified in exon 10. More recently, additional mutations have been found in exons 2, 5 and 10, bringing the current total of known mutations to twelve. ${ }^{16}$ The protein encoded by the gene, named pyrin ${ }^{14}$ or marenostrin, ${ }^{15}$ is a member of a family of nuclear factors homologous to the Ro52 autoantigen.

Some recent studies have reported conflicting and inconclusive results with regard to the association between homozygosity for Met694Val and amyloidosis. ${ }^{17-19}$ The aim of our study was to characterise the mutations in the M E FV gene in different ethnic groups, and to examine whether there is a correlation between the different mutations and the clinical symptoms in affected individuals. Specifically, we examined whether there is an association between FMF genotype and amyloidosis.

\section{Subjects and Methods}

In order to establish the frequency of the mutations in different ethnic groups, we studied 83FMF families from three ethnic groups: $41 \mathrm{~N}$ orth A frican Jewish families (from Morocco, A Igeria, Tunisia and Libya) (140 individuals, 65 affected), $16 \mathrm{~A}$ rmenian families living in the U SA ( 82 individuals, 31 affected), and 26 Turkish families (76 individuals, 42 affected). M ost families were multiplex with two or more affected members, and in ten families a parent, an aunt or an uncle of the proband was also affected. I nitially 134 affected individuals were identified in these families based on accepted clinical criteria ${ }^{7}$ (Table 1). Following determination of the mutations at the MEFV locus, ten asymptomatic individuals were found to carry mutations in both alleles and were therefore considered genetically affected. Six individuals, who were clinically diagnosed as having FMF and treated with colchicine, were found not to carry the same mutations as their affected siblings or any of the other known mutations. They were, therefore, considered unaffected and excluded from the statistical analysis. Thus there were 138 affected and 160 unaffected individuals in the study population.

A detailed family history and a pedigree were obtained by interviewing each patient, and a comprehensive medical history was taken from each family member.

Of the patients studied, 20 had amyloidosis diagnosed by rectal and/or renal biopsy: ten non-A shkenazi Jews, one A rmenian and nine Turks. In all cases amyloidosis was diagnosed in previously untreated or inadequately treated patients.

Table 1 The FMF study population, first based on clinical criteria alone and then in combination with DNA testing

\begin{tabular}{lccc}
\hline & $\begin{array}{c}\text { North A frican } \\
\text { J ews }\end{array}$ & A rmenians & Turks \\
\hline Families, no. & 41 & 16 & 26 \\
$\begin{array}{l}\text { Patients based on clinical } \\
\text { criteria alone, no. }\end{array}$ & 62 & 31 & 41 \\
$\begin{array}{l}\text { A symptomatic FM F based } \\
\text { on D N A testing, no. }\end{array}$ & 5 & 2 & 3 \\
$\begin{array}{l}\text { Clinically diagnosed FM F } \\
\text { disproved by D NA testing, no. }\end{array}$ & 2 & 2 & 2 \\
\begin{tabular}{l} 
Total FM F patients \\
\hline
\end{tabular} & 65 & 31 & 42 \\
\hline
\end{tabular}


A ffected individuals were assigned according to the FM F mutation to one of the following groups: homozygotes for the mutation $\mathrm{Met} 694 \mathrm{Val}$, heterozygotes for this and another mutation, and homozygotes or heterozygotes for any two mutations other than M et694Val.

Variables related to the FMF phenotype such as: age of onset of the inflammatory attacks, number of attacks in a year, age of commencement of colchicine treatment, the presence of fever during attacks, the organs involved in the inflammatory process, and the presence of amyloidosis were compared between the different genotype groups. We also compared the clinical characteristics of the FM F patients with and without amyloidosis within each genotype (statistical analysis was performed when the number of patients was large enough to allow meaningful comparisons).

Statistical analysis was performed using Student's t test for two-group comparisons of continuous variables and analysis of variance for multiple groups comparisons. The $\chi^{2}$ analysis was used to test for the significance of the association between the clinical characteristics of $F M F$ and the presence of amyloidosis and the different genotypes. Fisher's exact test was performed to test for significance of the association when the sample size was small (expected counts in each cell less than 5).

Since awareness of the diagnosis of FMF may vary in different ethnic groups, especially in I srael where the disease is very common among the NAJ, we analysed the group of NA J patients separately. Since only two NAJ patients were not homozygotes for the M et694Val mutation, we excluded them from the genotype-phenotype correlation analysis, and thus analysis was performed on four groups of patients: NA J homozygotes for the Met694Val mutation, homozygotes for this mutation from other ethnic groups, compound heterozygotes from all ethnic groups where one allele carried this mutation, and patients not carrying this mutation at all.

\section{Mutation Identification}

The region that harbours the four common mutations in Exon 10 was amplified with PCR and specific primers: 10F 1 , $5^{\prime}$-ccagaagaactaccctgtccc-3' and 10R 1, 5'-cagagcagctggcgaatgtat-3'. PCR conditions were denatured at $95^{\circ} \mathrm{C}$ for $10 \mathrm{~min}$; 30 cycles of $95^{\circ} \mathrm{C}$ for $15 \mathrm{~s}, 55$ for $30 \mathrm{~s}$ and 72 for $3 \mathrm{~min}$, with a final extension at 72 for $10 \mathrm{~min}$. PCR products were purified with Sephadex P100 chromatography and sequenced directly, using specific primers and A mpliTaq FS D ye Termination cycle sequencing kit.

This study was approved by the $\mathrm{H}$ uman Subjects $\mathrm{Commit-}$ tees at the $\mathrm{R}$ abin Medical Center, Beilinson Campus, Petah Tikva, Israel, and the Cedars-Sinai Medical Center, Los A ngeles, California, and informed consent was obtained from each participant.

\section{Results}

Table 2 depicts the distribution of the four most common mutations in exon 10 of the MEFV gene in independent FMF chromosomes in each ethnic group. $M$ utation $M$ et694Val was the most common mutation in each ethnic group, being significantly more frequent in $N A$ J compared with other ethnic groups $(P<0.001)$.
The second most common mutation, Val726A la, was found in $11 \%$ of A rmenian and $12 \%$ of Turkish affected chromosomes. Two other mutations were found: M et680l le, which was present in $1 \%$ of NAJ, $24 \%$ of A rmenian and $11 \%$ of Turkish carrier chromosomes, and Met694lle, which was present in $2 \%$ of Turkish carrier chromosomes. In 16 carrier chromosomes of clearly affected individuals no known mutation was identified (Table 2).

Table 3 summarises the clinical characteristics of the patients according to the different genotype groups. The NA J homozygotes for the mutation M et694Val had a significantly earlier age of onset of FM F inflammatory attacks in comparison with the group of patients homozygous for this mutation in other ethnic groups (Turks and A rmenians) $(4.7 \pm 3.4$ vs $9.7 \pm 8.1$, $\mathrm{P}<0.0003)$. They also commenced colchicine treatment at an earlier age $(8.8 \pm 8.1$ vs $24.5 \pm 16.5$, $P<0.0001)$. There was no significant difference in the mean number of attacks in a year between these groups. Pleuritis was significantly more common among the Turks and Armenians than among the NAJ $(P<0.001)$. A myloidosis was less prevalent among the NAJ patients, although the difference did not reach statistical significance $(16 \%$ vs $33 \%, \quad P=0.08)$ (Table 4).

In the group of patients of Turkish and A rmenian origin there were no significant differences between the different genotypes in parameters related to the severity of the FMF disease such as age of onset of

Table 2 D istribution of the four most common M EFV gene mutations in exon 10 among independent FM F chromosomes according to the different ethnic groups

\begin{tabular}{lccc}
\hline & $\begin{array}{c}\text { North A frican } \\
\text { J ews } \\
(n=83)^{a}\end{array}$ & $\begin{array}{c}\text { A rmenians } \\
(n=37)\end{array}$ & $\begin{array}{c}\text { Turks } \\
(\mathrm{n}=56)\end{array}$ \\
\hline M et694Val & $80(97 \%)$ & $18(49 \%)$ & $34(61 \%)$ \\
Val726A la & - & $4(11 \%)$ & $7(12 \%)$ \\
M et680l le & $1(1 \%)$ & $9(24 \%)$ & $6(11 \%)$ \\
M et694lle & - & - & $1(2 \%)$ \\
Others & $2(2 \%)$ & $6(16 \%)$ & $8(14 \%)$ \\
\hline
\end{tabular}

$\mathrm{a}=$ number of independent chromosomes. Only chromosomes from unrelated individuals were used for this analysis. Note: The number of independent chromosomes per family may be greater than 2 . This is the case if an affected individual marries a carrier, resulting in affected parents producing affected offspring, and also in a situation where a carrier married to another carrier has affected siblings. 
symptoms, age at diagnosis, number of attacks in a year and the organs involved in the attacks.

A statistically significant association was found between the mutation $\mathrm{M}$ et694Val and amyloidosis $(P=0.02)$ (Table 4). This was confirmed when analysis was done separately on the group of Turkish and A rmenian patients. Whilst eight out of $24 \mathrm{FM} \mathrm{F}$ patients homozygous for the Met694Val mutation were diagnosed with amyloidosis, only two heterozygotes had amyloidosis ( $P=0.004)$.

Since FM F amyloidosis can be prevented by colchicine treatment, we tested whether the association between the M et694Val mutation and amyloidosis held in patients who had never received colchicine and developed amyloidosis prior to age 20. The prevalence of amyloidosis developing between the ages of 13 and
20 in untreated homozygotes for this mutation was $67 \%$ (10 out of 15) in NAJ and 57\% (8 out of 14) in Turks and A rmenians. These rates were significantly higher than those in compound heterozygotes $(10 \%, \mathrm{P}=0.001$ and $P=0.007$ respectively, Table 4).

\section{Discussion}

We have demonstrated in this study that the four common exon 10 mutations of the MEFV gene account for $98 \%$ of the affected chromosomes in the North A frican Jews, $84 \%$ in the A rmenians and $86 \%$ in the Turks. Thus, a relatively simple molecular test can provide an accurate diagnosis in a large proportion of FM F patients.

Table 3 Characteristics of symptoms in F M F patients according to the different M E FV gene mutations

\begin{tabular}{|c|c|c|c|c|}
\hline & \multirow{2}{*}{$\begin{array}{c}\text { NAJ } \\
\text { Homozygote } \\
\text { M et694Val } \\
(n=63)^{a}\end{array}$} & \multicolumn{3}{|c|}{ Turks and A rmenians } \\
\hline & & $\begin{array}{l}\text { Homozygote } \\
\text { M et694Val } \\
(n=24)\end{array}$ & $\begin{array}{l}\text { H eterozygote } \\
\text { M et694Val/other } \\
(n=41)\end{array}$ & $\begin{array}{l}\text { Non- } \\
\text { M et694Val } \\
(n=8)\end{array}$ \\
\hline M ale/female & $29 / 34$ & $14 / 10$ & $23 / 18$ & $4 / 4$ \\
\hline A ge of onset, yrs & $4.7 \pm 3.4^{c}$ & $9.7 \pm 8.1$ & $10.6 \pm 8.1$ & $14.9 \pm 8.2$ \\
\hline A ttacks/yr, no. & $10.1 \pm 7.1$ & $8.0 \pm 5.7$ & $9.9 \pm 10.6$ & $5.3 \pm 5.9$ \\
\hline Treatment age, yrs & $8.8 \pm 8.1^{d}$ & $24.5 \pm 16.5$ & $23.5 \pm 10.3$ & $20.6 \pm 11.8$ \\
\hline A ge diagnosis of amyloidosis, yrs & $24.2 \pm 9.1$ & $23.5 \pm 3.4$ & $21.0 \pm 8.0$ & - \\
\hline A symptomatic, no. & 5 & 2 & 3 & - \\
\hline Fever $^{b}$ & $53(91 \%)$ & $22(100 \%)$ & $37(92 \%)$ & $7(89 \%)$ \\
\hline Peritonitis $^{b}$ & $44(76 \%)$ & $21(95 \%)$ & $34(85 \%)$ & $8(100 \%)$ \\
\hline Pleuritis $^{b}$ & $12(21 \%)$ & $12(54 \%)$ & $19(48 \%)$ & $3(37.5 \%)$ \\
\hline A rthritis ${ }^{b}$ & $26(45 \%)$ & $10(45 \%)$ & $14(35 \%)$ & $2(25 \%)$ \\
\hline A ge at ascertainment, yrs & $19.0 \pm 11.4^{d}$ & $32.6 \pm 17.0$ & $36.0 \pm 14.8$ & $26.7 \pm 10.0$ \\
\hline
\end{tabular}

$\mathrm{a}=$ number of FM F patients; ${ }^{\mathrm{b}}$ in parenthesis: percentage of patients with a specific symptom out of all symptomatic patients; ${ }^{\mathrm{c}} \mathrm{NAJ}$ vs homozygotes M et694Val Turks and A rmenians, $P<0.001$; $N A$ J vs homozygotes M et694Val Turks and $A$ rmenians, $P<0.0001$.

Table 4 A myloidosis in FM F patients according to the various M E FV gene mutations

\begin{tabular}{lcccc}
\hline & $\begin{array}{c}\text { NAJ } \\
\text { Homozygote } \\
\text { Met694Val }\end{array}$ & $\begin{array}{c}\text { Homozygote } \\
\text { M et694Val }\end{array}$ & $\begin{array}{c}\text { Turks and A rmenians } \\
\text { M et694Val/other }\end{array}$ & $\begin{array}{c}\text { Non- } \\
\text { M et694Val }\end{array}$ \\
\hline Total patients with amyloidosis & $10 / 63(16 \%)$ & $8 / 24(33 \%)$ & $2 / 41(5 \%)$ & $0 / 8^{\mathrm{a}}$ \\
$\begin{array}{l}\text { Patients (of the total with amyloidosis) } \\
\text { not treated and developed amyloidosis } \\
\text { prior to age 20, no. }\end{array}$ & $10 / 15(67 \%)$ & $8 / 14(57 \%)$ & $2 / 19(10 \%)$ & \\
\hline
\end{tabular}

" comparison between the three genotypes in Turks and A rmenians (homozygotes vs heterozygotes vs non-carriers of the $\mathrm{M}$ et694V al mutation), $\mathrm{P}=0.001$. 
In addition to its value in considering whether to give colchicine or not, detection of the mutation allows identification of FM F patients at the presymptomatic stage, some of whom may present with amyloidosis as the first symptom (FM F type 2).

In our study population there were no significant differences in the clinical presentation of $\mathrm{FMF}$ patients carrying different mutations, although both Pras et $\mathrm{al}^{20}$ and Dewalle et $\mathrm{al}^{17}$ found that homozygosity for the $M$ et694Val mutation was significantly associated with a more severe form of the disease. A possible explanation could be that the NAJ patients have a phenotype which is different from that of other ethnic groups, even when they have the same genotype. We did, in fact, find such differences between the NAJ and the Turks/A rmenian homozygous for Met694Val, but no differences between genotypes within the same ethnic group. The previous studies did not control for ethnicity.

Within each genotype, we found no differences in parameters related to the severity of the disease between patients with and without amyloidosis, but a significant association was found between the mutation $\mathrm{M}$ et694Val and the development of amyloidosis. The finding that amyloidosis is associated with a certain genotype which within our study population was not correlated with a more severe clinical disease suggests that amyloidosis is not related to the severity of $F M F$, but rather is inherent in the specific MEFV mutation. This is also supported by earlier reports that showed no correlation between the severity of the disease and amyloidosis, and the fact that some patients developed amyloidosis prior to FMF episodes. ${ }^{7,11}$ In addition, some patients with FM F do not benefit from colchicine in terms of prevention of attacks, yet do not develop amyloidosis while on this treatment.

Even though in our study population no cases of amyloidosis were found in patients who did not carry at least one $\mathrm{M}$ et694Val mutation, there have been three recent reports of such an association. $Y$ alçinkaya et al ${ }^{18}$ reported two patients with amyloidosis who were both

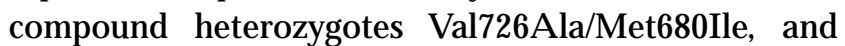
D ewalle et $\mathrm{al}^{17}$ reported an A rab kindred where all the affected individuals were homozygotes for M et694lle. The third case, reported by Pras, ${ }^{19}$ was one patient with systemic amyloidosis who was homozygous for Val726A la. O ur study allows for the first time statistical analysis of the genotype-phenotype correlation with regard to amyloidosis and demonstrates a significant association between $\mathrm{M}$ et694Val and this complication.
Of interest are the findings of earlier age of onset and earlier age at commencement of colchicine treatment in J ews of North A frican origin compared with Turks and A rmenians, all homozygotes for M et694Val. These differences may be explained by a greater awareness of FMF among North A frican Jews in I srael leading to earlier diagnosis and treatment. Earlier age of treatment may account also for the relatively lower prevalence of amyloidosis observed in this study in North A frican Jewish homozygotes for M et694Val compared with the A rmenians and Turks. Supporting this is the finding that the prevalence of amyloidosis was similar in both groups when patients younger than age 20 and those who had been treated with colchicine prior to age 20 were excluded. Pleuritis was significantly less frequent in NAJ patients. This finding is at variance with that of Dewalle et al, ${ }^{17}$ who found that both pleuritis and arthritis were significantly more frequent in homozygotes for the M et694Val mutation. H owever, since FMF is diagnosed and colchicine treatment commenced at an earlier age in the NAJ group compared to in other groups, this could be due to underdiagnosis of pleuritis in these young patients.

Our findings may have important clinical implications for the treatment of FM F families. Since colchicine has been shown to prevent the development of amyloidosis, ${ }^{9,10}$ lifelong treatment is recommended for all FM F patients. Based on our findings, it appears that homozygotes for $\mathrm{M}$ et694Val are at the highest risk, and should be given colchicine treatment for life. If further studies confirm these findings, the question of treating asymptomatic individuals homozygotes for the $M$ et694Val mutation with colchicine and withholding it from mildly affected patients who do not carry this mutation will need to be addressed.

\section{Acknowledgements}

The authors thank the FM F families for participating in the study. This project was partially supported by research awards from the US-Israel BSF grant No.93-00109 (MS), the E uropean community (Y D ), the A rthritis Foundation (NFG), and the Cedars Sinai Board of Governors Chair of M edical Genetics ( $\mid R$ ).

\section{References}

1 Sohar E, Gafni J, Pras M, Heller H: Familial Mediterranean fever. A survey of 470 cases and review of the literature. A m J M ed 1967; 43: 227-253. 
2 Daniels $M$, Shohat T, B renner-U IIman A, Shohat $M$ : Familial M editerranean fever: high gene frequency among the non-A shkenazic and A shkenazic Jewish populations in I srael. A m J M ed G enet 1995; 55(3): 311-314.

3 Rogers DB, Shohat $M$, Petersen GM et al: Familial $M$ editerranean fever in A rmenians; autosomal recessive inheritance with high gene frequency. Am J M ed G enet 1989; 34: 168-172.

4 Schwabe A D, Peters R S: Familial Mediterranean fever in A rmenians. A nalysis of 100 cases. Medicine (Baltimore) 1974; 53: 453-462.

5 Tauber T, Zimand S, Kutzer E : R ecurrent pericarditis in familial Mediterranean fever. Harefuah 1995; 128: 611-612.

$6 \mathrm{G}$ afni J, Ravid M, Sohar E: The role of amyloidosis in familial Mediterranean fever: a population study. Isr J Med Sci 1968; 4: 995-999.

7 Pras M, Bronshpigel N, Zemer D, Gafni J: Variable incidence of amyloidosis in familial Mediterranean fever among different ethnic groups. The Johns $\mathrm{H}$ opkins M edical Journal 1982; 150: 22-25.

$8 \mathrm{H}$ eller H, Sohar E, Sherf L: Familial M editerranean fever. A rch Intern M ed 1958; 102: 50-71.

9 Zemer D, Pras M, Sohar E et al: Colchicine in the prevention and treatment of the amyloidosis of familial Mediterranean fever. N Engl J Med 1986; 314: 1001-1005.

10 Livneh A, Zemer D, Langevitz ZP et al: Colchicine treatment of $A A$ amyloidosis in familial Mediterranean fever. A rthritis R heum 1994; 37: 1804-1811.

11 Heller H, Sohar E, Gafni J, Heller J: A myloidosis in familial Mediterranean fever. A $n$ independent genetically determined characteristic. Arch Intern Med 1961; 107: 539-550.
12 Pras E, A ksentijevich I, G ruberg L et al: M apping of a gene causing familial Mediterranean fever to the short arm of chromosome 16. N Engl J Med 1992; 326: 1509-1513.

13 Shohat $M, B u X$, Shohat $T$ et al: The gene for familial $M$ editerranean fever in both A rmenians and non-A shkenazi J ews is linked to the alpha-globin complex on 16p: evidence for locus homogeneity. A m J H um G enet 1992; 51: 1349-1354.

14 The International FMF Consortium: A ncient missense mutations in a new member of the R oR et gene family are likely to cause familial M editerranean fever. Cell 1997; 90: 797-807.

15 The French FMF Consortium: A candidate gene for familial M editerranean fever. Nat G enet 1997; 17: 25-31.

16 Bernot A, da Silva C, Petit JL et al: Non-founder mutations in the MEFV gene establish this gene as the cause of familial Mediterranean fever. $\mathrm{H}$ um $\mathrm{M}$ ol $\mathrm{G}$ enet 1998; 7(8): 1317-1325.

17 D ewalle M, D omingo C, R ozenbaum M et al: Phenotypegenotype correlation in Jewish patients suffering from familial Mediterranean fever (FMF). Eur J Hum G enet 1998; 6: 95-97.

18 Yalçinkaya F, A kar N, Misirlioglu M: Familial Mediterranean fever-amyloidosis and the Val726A la mutation. (L etter). N E ngl J Med 1998; 338: 993.

19 Pras M: Familial M editerranean fever: From the clinical syndrome to the cloning of the pyrin gene. Scand J Rheumatol 1998; 27: 92-97.

20 Pras E, L angevitz P, L ivneh A et al: G enotype-phenotype correlation in familial M editerranean fever (a preliminary report). In: Sohar E, G afni J, Pras M (eds). Familial Mediterranean Fever. Freund Publishing House: Tel A viv, 1997, pp 260-264. 